\title{
Walking for Transportation on Campus: Perspectives from Faculty and Students
}

\author{
Jennifer McMullen, Ph.D. \\ Sarah Kercsmar, Ph.D. \\ Kimberly Poole, M.S., CHES \\ Melinda J. Ickes, Ph.D. \\ University of Kentucky
}

\begin{abstract}
Background: Walking is a recommended strategy for meeting physical activity (PA) requirements and benefiting from associated health outcomes. Walking for transportation, which is walking to get from "Point A" to "Point B," may help individuals in fulfilling their weekly recommended PA, though little research has been done as it relates to walking for transportation on a college campus.

Aim: To qualitatively explore attitudes and barriers toward walking for transportation and cues to action among a convenience sample of faculty, staff, and students.

Methods: Through a non-experimental design, qualitative data were collected through conducting focus groups $(\mathrm{n}=10)$ at a public, southeastern university with college students, staff, faculty ( $\mathrm{n}=13$ students; $\mathrm{n}=25$ staff; $\mathrm{n}=19$ faculty).

Results: The main themes emerging included: definitions of walking for transportation, factors that encouraged walking for transportation, barriers to walking on campus, and campaign/incentive suggestions.

Conclusion: Findings support previous research which indicates situational factors prohibit individuals from walking for transportation. Further, findings indicate it would be of value for future research to determine best practices for promoting and incentivizing walking across various sub-groups not explored in this study. Lastly, point-of-decision prompt use (i.e., campus signage to promote walking) should be explored as a strategy to promote walking and active transport to determine what various groups respond most positively to.
\end{abstract}

Submitted 6 October 2019: accepted 8 November 2019

Keywords: walking for transportation, campus, college

The prevalence of adult obesity in the United States is approximately 39.8\%, impacting around 93.3 million adults (Centers for Disease Control and Prevention [CDC], 2018). Obesity has been associated with poor mental health, reduced quality of life, and is a common risk factor among the leading causes of death in the U.S. including diabetes, heart disease, stroke, and some cancers (CDC, 2017). The importance of physical activity (PA) as it relates to the improvement of individuals' health and prevention of obesity has been made clear across the literature. Positive health outcomes associated with engaging in PA include, but are not limited to, a significant reduction in the risk of chronic disease and the promotion of positive mental health (2008 Physical Activity Guidelines for Americans, 2008). 
Individuals may benefit from these positive outcomes through walking or adding walking to other forms of PA (CDC, 2016). Walking is recommended to obtain health benefits and meet PA requirements. In the literature, walking is often spoken of in terms of walking for leisure or walking for transportation. Walking for transportation is defined as, "walking to get to and from places" (Cerin, Leslie, \& Owen, 2009; Craig et al., 2003). In the U.S., less than onethird of adults walk for transportation, even though walking for transportation is linked with higher overall levels of PA (Paul, Carlson, Carroll, Berrigan, \& Fulton, \& 2015; Wanner, Gotschi, Martin-Diener, Kahlmeier, \& Martin, 2012).

Attitude toward walking is positively associated with walking for transportation (Yang \& Diez-Roux, 2016). In a study with college students, it was indicated that attitude toward walking had an effect on their walking behavior (Sun, Acheampong, Lin, \& Pun, 2015). However, there is limited research with this topic on college campuses, especially as it pertains to the attitudes and beliefs of college faculty and staff, thus creating a potential to reach diverse audiences. As walking for transportation may provide individuals in academic communities adequate PA, exploratory research is needed to further understand what may promote or inhibit walking for transportation among individuals in a campus community.

Given the limited research in this area, this study qualitatively explored attitudes and barriers toward walking for transportation and cues to action among a convenience sample of faculty, staff, and students at a large southeastern university.

\section{METHODS}

\section{Design and Population}

A non-experimental design was used to collect qualitative data through focus groups during the 2017-2018 academic year. The study was approved by the university's Institutional Review Board. Participants included a convenience sample of students, staff, and faculty recruited from a public university in the southeast. During the study period, university enrollment was approximately 30,000 undergraduate and graduate students, with the majority White/NonHispanic and a fairly even split between male and female. The university reported approximately 9,300 staff and 2,300 faculty during this time; $80 \%$ identified as White/non-Hispanic. A total of 97 individuals signed up for the focus groups (23 students, 50 staff, 24 faculty) through the procedures described below. A total of 57 participated (13 students, 25 staff, 19 faculty), resulting in a 59\% participation rate of those who expressed interest. It is not possible to calculate reach of the recruitment methods, nor were additional demographic data collected from those who signed up and/or participated.

\section{Measures}

A focus group guide was developed by the researchers to further explore walking for transportation among various populations served by the university. Questions were driven by the findings associated with a larger study, which evaluated the impact of WalkUK, a point-of-decision prompt campaign designed to promote walking for transportation on and around a university campus (Ickes et al., 2018; McMullen \& Ickes, 2018). Content validity was affirmed through a panel of three experts in behavior change, theoretical application, and/or qualitative research. They were asked to review the questions and confirm appropriateness as it pertained to the study's research questions and underlying theoretical underpinnings. 
All focus group sessions opened with introductions followed by a set of standardized questions, while still allowing for topics that emerged as a result of interactions between participants. The focus group questions are in Table 1.

Table 1

Focus Group Questions

1. Have you ever heard of the term walking for transportation? What does it mean to you? Can you give us some examples?

2. Walking for transportation has been defined as walking for the sake of getting somewhere, to get from one place to another, a mode of transportation. Given that definition, do you walk for transportation? Can you tell us a little bit more about that? What kinds of places are you most likely to walk to? Probe for employees: do you find yourself walking for transportation while at work?]

3. What do you think encourages someone to walk for transportation? [If it doesn't come up: Do you like to walk for transportation by yourself or prefer to walk with others?]

4. Do you think walking for transportation can help contribute to meeting the recommended PA requirements per day? Why or why not?

5. Do you think if people knew walking for transportation could contribute to meeting the daily requirements that it would encourage them to do so? What would be some ways we might help inform people that this is the case?

6. Do you find yourself walking more for leisure or recreation as compared to transportation? Please explain.

7. What are some of the barriers you face related to walking for transportation?

On our campus? Where you live?

8. What strategies might promote walking for transportation among your peers/colleagues?

9. Have you seen signs around campus or in your community promoting walking for transportation or leisure? Do you think there is a need for this type of campaign on college campuses? In your community? Please explain.

10. Here is an example of a sign we used to promote walking for transportation on campus. What are your thoughts? Do you have suggestions on what might be added to the signs to promote walking?

11. Of all the things we've discussed today, is there anything else you would like to share about walking for transportation? 


\section{Procedures}

Individuals were recruited via email through existing university listservs for students, staff, and faculty, respectively. The email included details on the study as well as dates and times of the scheduled focus groups. Individuals could then click a link to sign-up for the specific date/time they were interested in. Individuals who expressed an interest in participating received a follow-up email a week before and the day of the scheduled focus group indicating date, time, location and logistics, as well as additional contact information if they had questions or concerns. Researchers conducted a total of ten focus groups, ranging in size from 2 to 12 participants. In total, there were 13 students and 42 faculty/staff.

Participants were given a document of informed consent upon arrival at the focus group that was reviewed with them by study personnel prior to beginning the focus group. A trained member of the research team facilitated the focus groups. Training included going over the script, potential questions for the focus group, techniques on how to probe participants for further response, etiquette on maximizing participant comfort in discussing personal viewpoints and maintaining confidentiality. The focus groups lasted approximately one hour in duration and were both recorded and notes were taken to ensure accuracy of comments. This was reinforced with the participants and also stated on the consent form. Participants received a $\$ 25$ gift card for their participation in the focus group.

\section{Data Analysis}

The focus groups $(n=10)$ were transcribed and cleaned to prepare for analysis. A codebook was created by three members of the research team using an inductive model of analysis (Thomas, 2006). One transcript was chosen for initial review and each research team member independently coded the transcript for themes. The researchers then met together to compare themes and create a codebook of the most commonly referenced concepts. Once the initial codebook was developed, the three research team members chose another transcript to code individually as a norming process and then compare to make sure codes were all being applied in a consistent manner across coders.

Next, each focus group transcription was coded by the three researchers individually until theme saturation was reached. The codebook was treated as a living document and additional codes were added as the analysis process progressed. Unique codes related specifically to students, faculty, or staff were also generated as appropriate. The team then met to review the transcripts for consistency and discuss the overarching themes that emerged.

\section{RESULTS}

Considering the relatively small sample size in each subgroup (e.g., students, faculty, and staff), the themes are summarized as a whole, rather than each subgroup. Definitions of walking for transportation, factors that encouraged walking for transportation, barriers to walking on campus, and campaign/incentive suggestions were the main topics discussed within the focus group sessions.

\section{Walking for Transportation Defined}

Walking for transportation was defined by the focus group participants as moving from one part of campus to the other once parking for the day. While they discussed walking to campus, most participants dismissed that as a feasible 
mode of walking for transportation due to the distance from their home to work. Participants noted "everybody does it [walking for transportation] on campus" and "we have less parking, so we walk [from our parked cars off-campus]."

Focus group participants identified a number of factors that encouraged walking for transportation on campus, (see Table 2) an attitude toward behavior that leads to behavioral intention and ultimately, behavior. The themes that emerged under this umbrella were in two major categories- factors that currently encourage walking for transportation and factors that could encourage more walking for transportation on campus. In the first category, participants noted that parking once and not moving their cars, saving money and time, and avoiding all the barriers noted in the next section were factors that currently encourage them to walk for transportation. When probed further, participants discussed increasing the number of crosswalks and covered sidewalks as factors that could encourage more walking for transportation on campus.

Interestingly, there were a few themes that emerged that the research team expected at the beginning may be strong factors in favor of walking for transportation, but instead, they were more neutral in the focus group interviews. These themes included viewing walking as a necessity, a lack of importance placed on walking together versus walking alone, and a lack of clear concern for health as a major factor in walking for transportation. Participants noted that having someone to walk with and the health benefits were not major factors in encouraging them to walk more.

Table 2

Factors that Encourage Walking for Transportation on Campus (Questions 3, 4, 8)

\begin{tabular}{|c|c|}
\hline $\begin{array}{l}\text { Factors that Currently Encourage } \\
\text { Walking for Transportation }\end{array}$ & $\begin{array}{c}\text { Factors that Could Encourage More Walking for } \\
\text { Transportation }\end{array}$ \\
\hline $\begin{array}{l}\text { "Most efficient way...to get from one } \\
\text { side of campus to the other." }\end{array}$ & $\begin{array}{l}\text { "Covered sidewalks... so when it's raining you wouldn't } \\
\text { have to be outside. You're still outside, but you're } \\
\text { covered." }\end{array}$ \\
\hline $\begin{array}{l}\text { "Appreciate not having to wait for all } \\
\text { the traffic and things." }\end{array}$ & $\begin{array}{l}\text { "Crosswalks and people ignoring crosswalks...when } \\
\text { people walk, do they feel safe?”" }\end{array}$ \\
\hline $\begin{array}{l}\text { "Pay less for parking the further out } \\
\text { you park" }\end{array}$ & "Wider pathways to walk..." \\
\hline $\begin{array}{l}\text { "Don't have to depend on buses and } \\
\text { who knows how long it will take." }\end{array}$ & $\begin{array}{l}\text { "Shade, good lighting, safe pathways, not noisy, high } \\
\text { visibility" }\end{array}$ \\
\hline "Fitbit challenges" & \\
\hline
\end{tabular}

Using the definition of walking for transportation presented at the beginning of this article, the focus group participants identified a number of barriers to walking for transportation on campus (see Table 3). The first theme that emerged as a barrier related to comfort and personal needs. Individuals commonly noted that improper shoes and attire, poor weather, lack of time, personal safety, emergency situations that would necessitate leaving campus 
quickly (i.e., leaving to pick up a sick child), and physical limitations were barriers to walking for transportation on campus. In terms of structural issues, themes of navigating construction on campus, exposure to smoking on campus, lack of clear walking paths and appropriate sidewalks, and locations of parking lots in relation to where individuals needed to be emerged as common themes.

Table 3

Barriers to Walking on Campus (Questions 7 \& 11)

\begin{tabular}{|l|l|}
\hline \multicolumn{1}{|c|}{$\begin{array}{c}\text { Barriers to Walking for Transportation } \\
\text { Comfort \& Personal Needs }\end{array}$} & \multicolumn{1}{c|}{$\begin{array}{c}\text { Barriers to Walking for Transportation } \\
\text { Structural Issues }\end{array}$} \\
\hline "Depends on the weather." & "Layouts of the paths you can take" \\
"Smoking [by others]." & $\begin{array}{l}\text { "Several sidewalks I noticed there not taken care } \\
\text { of...and you know you to try to avoid those or you } \\
\text { know this is a notorious construction zone so } \\
\text { "Footwear is a big thing for me..." }\end{array}$ \\
$\begin{array}{l}\text { "I mean I would walk for transportation all } \\
\text { the time if I didn't have the distance, or a } \\
\text { kid, or things like that. Cause even like a } \\
\text { bus thing doesn't work well for parents with } \\
\text { kids." }\end{array}$ & $\begin{array}{l}\text { you locked off. So you can't go that way. So I think if } \\
\text { see how the different paths are crossing and which } \\
\text { one need help and fix those up so they don't look } \\
\text { as scary or you don't have a safety hazard." }\end{array}$ \\
$\begin{array}{l}\text { "I've had a partial knee replacement. So I } \\
\text { have to be strategic about which way I walk } \\
\text { on campus because it is not conducive to } \\
\text { individuals who have any challenges that } \\
\text { way. The stairs and stuff... So I end up } \\
\text { taking the longer route that usually ends up } \\
\text { getting blocked." }\end{array}$ &
\end{tabular}

The final set of themes to be discussed were suggestions for incentives or future campaigns that participants articulated during the focus group that would encourage walking for transportation (see Table 4).

The major theme that emerged as it related to incentives was to increase campus challenges around walking. Faculty and staff have periodic Fitbit challenges with a chance to win prizes for walking and these challenges were noted as a big motivator to walking for transportation. Students also noted that challenges with a chance to win prizes would be a motivator to walking for transportation for them as well. An improved app that would track steps in addition to just show distance between buildings on campus was also noted as a motivator that could be tried in future campaigns.

Focus group participants were also asked whether the signage used in the previous campaign influenced their decisions to walk for transportation on campus. 
The theme that emerged around this topic was that signs did not seem to make a large impact on students, faculty, and staff, but participants thought that signs may be helpful to those visiting or new to campus. Additionally, a theme emerged that signs inside buildings on campus like parking garages or on stairs noting calories burned, and so forth. may function as a motivator in future campaigns.

\section{Table 4}

\section{Campaign Suggestions or Incentives}

\begin{tabular}{|c|c|}
\hline Suggestions for Future Campaigns & Suggestions for Future Incentives \\
\hline $\begin{array}{l}\text { "Signs near elevators about the benefits } \\
\text { of taking the stairs when you can." } \\
\text { "...somebody maybe calculated say 'hey, } \\
\text { you're in this dorm and you're going to } \\
\text { Chem Phys, this is how many steps you're } \\
\text { taking.' And somebody could look at that } \\
\text { and say 'oh, well I have to go to Chem } \\
\text { Phys, so I am taking this amount of } \\
\text { steps." } \\
\text { 'YYu could use the app to do a survey. } \\
\text { When you open the app, sometimes it } \\
\text { asks you a single question that you have to } \\
\text { answer before you can do anything else. } \\
\text { So very quickly you could gather stats } \\
\text { about how people walk and from where." }\end{array}$ & $\begin{array}{l}\text { "An incentive I thought about because you know } \\
\text { everybody worries about where they're going to park, } \\
\text { if you hit so many steps in a month you're put into a } \\
\text { drawing for maybe a set of five spots. So it's not just } \\
\text { one person, but maybe five people get that spot for a } \\
\text { month and it's designated. It could rotate." } \\
\text { "Yeah, I think the FitBit challenge was really good. } \\
\text { And I've seen other FitBit challengers that were even } \\
\text { more enticing. I mean my mom he one with her } \\
\text { interns. For every day that she met the } 10,000 \text { steps, } \\
\text { she built up points and the points she could then cash } \\
\text { in for like Amazon gift cards. She ended up getting } \\
\text { enough gift cards to take care of all the Christmas } \\
\text { gifts with. And she get on the treadmill like every } \\
\text { night and be like oh I'm Christmas shopping. But she } \\
\text { lost so much weight. She lost like } 20 \text { pounds, and } \\
\text { then she had all of our Christmas paid for with her } \\
\text { walking points." }\end{array}$ \\
\hline
\end{tabular}

\section{DISCUSSION}

Walking for transportation is defined as "walking to get to and from places" (Cerin et al., 2009; Craig et al., 2003). Most adults $(>90 \%)$ think transportation walking is a reasonable thing to do (Watson et al., 2015). However, the employee participants in this study did not consider walking to work as a feasible opportunity to walk for transportation given the distance of their home to the university. What primarily emerged was that walking for 
transportation after arriving to campus was not so much a choice, but rather a necessity, due to the reported lack of convenient on-campus parking. This finding provided context for the lack of health as a major factor in walking for transportation in this study. Given the limited research in this area, it reinforces the need to understand how various sub-groups contextualize walking for transportation. Moreover, there is a need to further understand how viewing walking for transportation as a necessity versus something one wants to do impacts related attitudes and intention to walk for transportation in the future.

In both the factors that influence walking for transportation and barriers that were articulated, structural issues rose to the top in areas of concern. From providing covered sidewalks to having safe, well-lit and accessible pathways, many of the suggestions noted would need to be addressed as part of a master plan on campus. While limited research in this area exists, our findings support previous research which indicates situational factors prevent individuals from walking for transportation (Dunton \& Schneider, 2006) and citing more than one environmental barrier to walking significantly decreases walking (Dawson et al., 2007). Interestingly, those who perceive situational factors as barriers also engage in less moderate PA overall (Dunton \& Scheider, 2006), which has clear health implications. Understanding environmental barriers and other influences on walking for transportation during the workday as well as outside of the workday may provide greater insight to support efforts to increase walking. Expanding this research to conduct observational studies assessing walkability would help support recommendations to campus administrators and those working on campus pedestrian planning.

While walking for transportation was discussed as a necessity by the focus group participants while on campus, the role of incentives in rewarding walking for transportation and potentially encouraging those who may not be engaging in the practice as frequently was clear with faculty, staff, and students. Fitbit challenges are one common strategy used to successfully engage campus employees to increase PA (Mason et al., 2018), but students also articulated a desire to participate in such challenges. Additionally, faculty and staff voiced a desire for incentives that went beyond getting swag and moved toward earning points for gift cards and "larger" prizes, as well as incentives for better parking access on campus as a reward for walking for transportation. Further, future research should include more diverse populations including individuals with disabilities, for whom walking for transportation on a college campus may pose additional barriers to be addressed.

While there has been a push to promote walking to work or walking for transportation as potential strategies to increase PA (National Institute for Health and Care Excellence, 2008), there may be a need to reframe the message to reach the intended audience. Similarly, addressing perceived barriers to walking for transportation may support these efforts.

Findings from this study indicate that it would be of value to determine how to best promote and incentivize walking among various sub-groups. In addition, there is a need to determine if there is a difference in approaches needed when considering walking specifically for leisure and/or PA versus walking for transportation. Further, the use of point-of-decision prompts (i.e., campus signage to promote walking) needs to be investigated as a strategy to promote walking and active transport to determine what various groups respond most positively to. Some signs may indicate calories burned for walking, others may indicate distance and/or total time to the destination. Additionally, an app for students, faculty, and staff indicating distances and steps between buildings was suggested as a possible strategy. Given the use of apps to promote health and PA, this idea should be further explored and evaluated to determine the potential impact on walking for transportation while on campus. It may also be impactful if future research focused on the impact of policy changes on a college campus and how that affects walking for transportation. 
Policy changes may include the addition of convenient and safe walking paths and an increase in areas with amenities for pedestrians. Including administrators in working toward policy changes is an important step in bringing about a change in the way that people perceive walking for transportation.

\section{LIMITATIONS}

The participants who self-selected into this study as part of the convenience sample may have been predisposed to be more interested in walking for transportation or interested in sharing barriers to walking for transportation on campus than those who did not participate in the study. Further, the focus group was limited to a one-time session and some may not have felt as comfortable sharing within that environment. Given the small sample size, we cannot assume that all student/faculty/staff voices were represented, and all campus environments are different, thus impacting generalizability. Additionally, the researchers focused on walkability and did not include those who might have physical disabilities and are unable to walk for transportation. As such, future research may want to be more inclusive when discussing these topics.

\section{CONCLUSION}

Given the need to increase PA among U.S. adults, there is promise in further exploring walking for transportation as a strategy to do so. However, considerations for population specific barriers, strategies to communicate opportunities for walking for transportation, and evaluation efforts with strategies used are critical. 


\section{REFERENCES}

2008 Physical Activity Guidelines for Americans. (2008). Retrieved from https://health.gov/paguidelines/2008/pdf/paguide.pdf

Centers for Disease Control and Prevention (2015). Why walk! Why not! Retrieved from www.cdc.gov/physicalactivity/walking/

Centers for Disease Control and Prevention (CDC; 2017). Overweight and obesity: Adult obesity causes and consequences. Retrieved from https://www.cdc.gov/obesity/adult/causes.html

Centers for Disease Control and Prevention (CDC; 2018). Overweight and obesity: Adult obesity facts. Retrieved from https://www.cdc.gov/obesity/data/adult.html

Cerin, E., Leslie, E., \& Owen, N. (2009). Explaining socio-economic status differences in walking for transport: an ecological analysis of individual, social, and environmental factors. Social Science and Medicine, 68(6). https://doi.org/10.1016/j.socscimed.2009.01.008

Craig, C.L., Marshall, A.L., Sjostrom, M., Bauman, A., Booth, M.L., Ainsworth, B.E., Pratt, M., Oja, P. (2003). International physical activity questionnaire: 12 country reliability and validity. Medicine in Science and Sports and Exercise, 35(8),1381-1395. https://doi.org/10.1249/01.MSS.0000078924.61453.FB

Dawson J., Hillsdon M., Boller I., \& Foster C. (2007). Perceived barriers to walking in the neighborhood environment: A survey of middle-aged and older adults. Journal of Aging and Physical Activity, 15, 318-335. https://doi.org/10.1123/japa.15.3.318

Dunton, G.F. \& Schneider, M. (2006). Perceived barriers to walking for transportation. Preventing Chronic Disease, 3 (4), A116.

Ickes, M., Erwin, H., McMullen, J., Bollinger, L., Wiggins, A., Berger, M., \& Cantrell, C. (2018, April). An evaluation of WalkUK: Wayfinding signs to promote walking for transportation among college students. Poster Presentation at the Society for Public Health Education 69th Annual Conference, Columbus, OH.

Mason, R., Ickes, M., Campbell, M., \& Bollinger, L. (2018). An incentivized, workplace physical activity intervention preferentially increases daily steps in inactive employees. American Journal of Health Promotion, 32 (3), 638-645. https://doi.org/10.1177/0890117117723803

McMullen, J., \& Ickes, M. (2018, August). WalkUK: Promoting physical activity among university employees using wayfinding signs. Poster session presented at the Kentucky Bike/Walk Summit, Lexington, KY.

National Institute for Health and Care Excellence. (2008). Promoting physical activity in the workplace. Manchester, UK: National Institute for Health and Care Excellence.

Paul, P., Carlson S., Carroll, D, Berrigan, D, \& Fulton, J. (2015). Walking for transportation and leisure among U.S. adults - national health interview survey 2010. Journal of Physical Activity and Health, 12(6). https://doi.org/10.1123/jpah.2013-0519

Sun, G., Acheampong, A.R., Lin, H., \& Pun, V.C. (2015). Understanding walking behavior among university students using theory of planned behavior. International Journal of Environmental Research and Public Health, 12, 13794-13806. https://doi.org/10.3390/ijerph121113794

Thomas, D. (2006). A general inductive approach for analyzing qualitative evaluation data. American Journal of Evaluation, 27(2), 237-246. https://doi.org/10.1177/1098214005283748

Wanner, M., Gotschi, T., Martin-Diener, E., Kahlmeier S., \& Martin B.W. (2012). Active transport, physical activity, and body weight in adults: A systematic review. American Journal of Preventive Medicine, 5. https://doi.org/10.1016/j.amepre.2012.01.030 
Watson, K.B., Carlson, S.A., Humbert-Rico, T., Carroll, D.D. \& Fulton, J.E. (2015) Walking for transportation: What do U.S. adults think is a reasonable distance and time? Journal of Physical Activity and Health, 12(1), S53-S61. https://doi.org/10.1123/jpah.2014-0062

Yang, Y., \& Diez-Roux, A. (2016). Adults' daily walking for travel and leisure: Interaction between attitude toward walking and the neighborhood environment. American Journal of Health Promotion, 31(5), 435-443. https://doi.org/10.1177/0890117116669278

Author correspondence may be addressed to:

Jennifer McMullen, Ph.D.

Lecturer

University of Kentucky

100 Seaton Building

1210 University Drive

Lexington, Kentucky 40506

Jennifer.e.mcmullen@uky.edu 